\title{
Heterochromia of the scalp hair
}

\section{Jianjun Qiao MD PhD, Hong Fang MD MPhil}

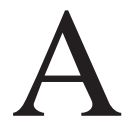

n 11-year-old Chinese boy with black hair and black eyes had a tuft of brown hair on the crown of his head that had been there since birth (Figure 1). The colour had not changed substantially over the years, and he was in good health. There was no history of similar hair findings in other members of his family. Physical examination revealed normal physical development, and the skin of his scalp was normal. Except for a tuft of brown hair on the vertex of his head, the colour of the rest of his hair, including his eyebrows and eyelashes, was black. His nails and teeth were normal, and he had no ocular or audiologic abnormalities. Under light microscopy, the brown hairs were thinner than the black hairs (Figure 2) and the pigmentation was homogeneous along the length of the hair shaft. A diagnosis of heterochromia of the scalp hair was made.

Heterochromia of the hair is described as the growth of hair with two distinct colours in the same person. ${ }^{1,2}$ When the distribution of the different-coloured hair is symmetric (e.g., lighter hair on the underarms, a red moustache on a person with otherwise brown hair), heterochromia of the hair is often physiologic. ${ }^{1,2}$ However, when heterochromia is asymmetrically distributed, it reflects a pigmentation disorder, which may have a genetic basis. ${ }^{2}$

In addition to being symmetric or asymmetric in location, heterochromic hair can be segmented or occur in tufts. Segmented heterochromia of the scalp hair, which is associated with iron deficiency anemia, is characterized by alternating dark and light segments on each hair. ${ }^{1}$ Our patient had a tuft of heterochromic hair that was distributed in a whorl pattern, consistent with the Blaschko lines of the vertex of the head, which was suggestive of somatic mosaicism of the genes affecting pigmentation. ${ }^{2}$ (Blaschko lines are skin lines invisible under normal conditions that may become apparent with some diseases of the skin or mucosa, and may represent fetal epidermal cell migration. ${ }^{3}$ ) Heterochromia of the hair that presents in tufts can also occur in specific pigmentary conditions, such as a tuft of dark coarse hair in a melanocytic nevus, hairs in vitiligo lesions, a band of white hair in children who have recovered from kwashiorkor and the white forelock in piebaldism.

From the Department of Dermatology, The First Affiliated Hospital, College of Medicine, Zhejiang University, Hangzhou, Zhejiang, China

CMAJ 2010. DOI:10.1503/cmaj092075

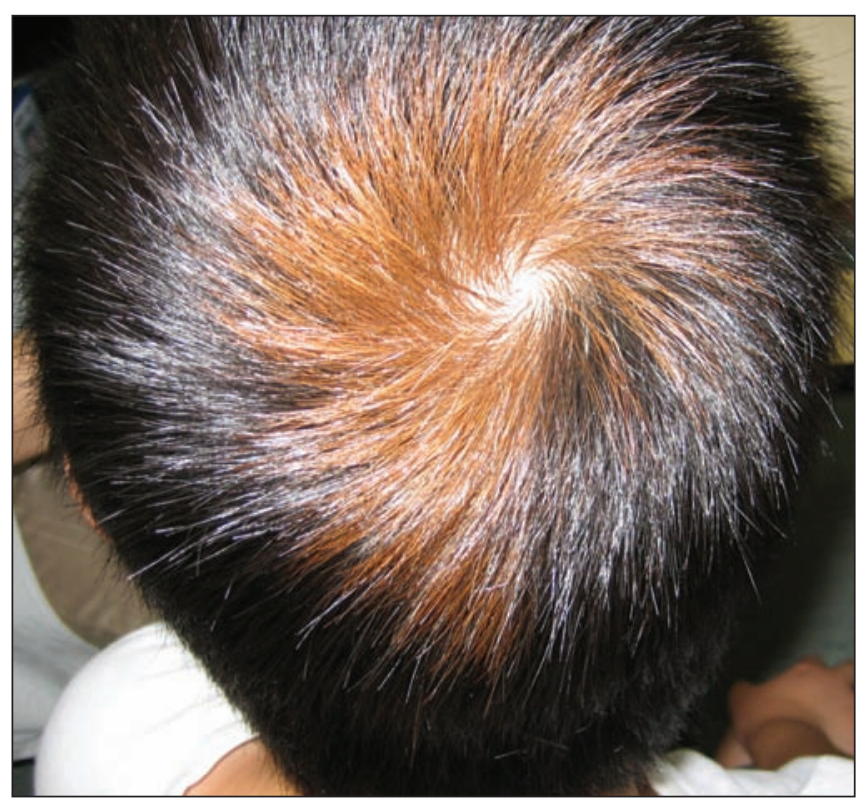

Figure 1: Heterochromia of the scalp hair of an 11-year-old boy.

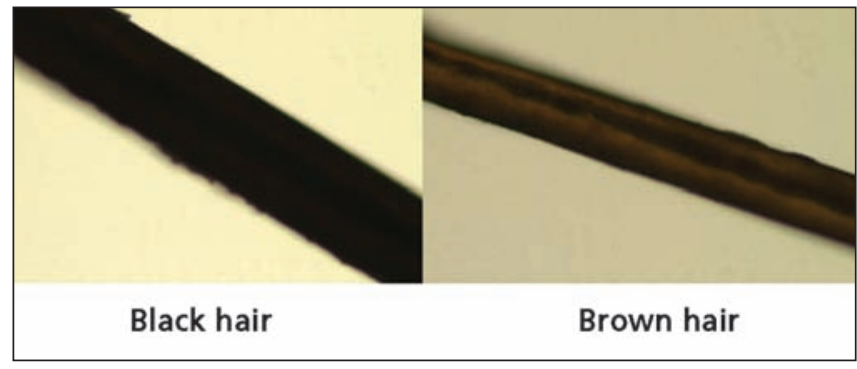

Figure 2: Under light microscopy, the brown hairs were thinner than the black hairs.

This article has been peer reviewed.

Competing interests: None declared.

\section{REFERENCES}

1. Yoon KH, Kim D, Sohn S, et al. Segmented heterochromia in scalp hair. J Am Acad Dermatol 2003;49:1148-50.

2. Iorizzo M, Piraccini BM, Tosti A. Heterochromia of the scalp hair following Blaschko lines. Pediatr Dermatol 2007;24:69-70.

3. Happle R, Assim A. The lines of Blaschko on the head and neck. J Am Acad Dermatol 2001;44:612-5. 